\title{
O COMPROMISSO DA VIGILÂNCIA SANITÁRIA COM A GARANTIA DO DIREITO À SAÚDE: EXPRESSÕES NO PLANO NACIONAL DE SAÚDE
}

\author{
The commitment of health surveillance in the guarantee of the right \\ to health: expressions in the Brazilian National Health Plan
}

Regina Célia Borges de Lucena*

\begin{abstract}
RESUMO
O presente trabalho tem por objetivo investigar a forma de inserção da noção de direito à saúde nos compromissos estabelecidos pela vigilância sanitária no Plano Nacional de Saúde (PNS). Foram identificados, nos PNS 2004-2007 e 2008-2011, os compromissos sob a responsabilidade da Agência Nacional de Vigilância Sanitária (Anvisa). Em seguida, realizou-se análise comparativa dos compromissos nos dois períodos. Observou-se que, no PNS 2004-2007, a maior parte dos compromissos da Agência estava relacionada à redução do risco de doença e ao acesso às ações e serviços de saúde. Já no PNS 2008-2011 nenhum dos compromissos assegurava a garantia do direito à saúde, por se tratar de mensuração de processos organizacionais da Agência. Tal distanciamento pode ser analisado sob o ponto de vista do embate entre garantia constitucional de direitos e submissão ao projeto político hegemônico num determinado contexto histórico.
\end{abstract}

Palavras-chave: Direito à Saúde; Planejamento em Saúde; Vigilância Sanitária.

\section{ABSTRACT}

This study aims to investigate the insertion mode of the right to health concept in the commitments made by health surveillance in the Brazilian National Health Plan (NHP). It was identified in the NHP 2004-2007 and 2008-2011, the commitments under the responsibility of the Brazilian National Health Surveillance Agency. Then, we carried out a comparative

\footnotetext{
* Doutora em Política Social, Universidade de Brasília; Especialista em Regulação e Vigilância Sanitária, Agência Nacional de Vigilância Sanitária. Brasília/DF - Brasil. E-mail: reginalucena@unb.br
}

Artigo recebido em: 02/07/2012. Aprovado em: 28/08/2012.

R. Dir. sanit., São Paulo, v. 14, n. 3, p. 95-111, nov. 2013/ fev. 2014 
analysis of the commitments in both periods. It was observed that in the NHP 2004-2007, most of the commitments of the Agency were related to risk reduction of disease and to access to health services and actions. In the NHP 2008-2011, none of the commitments ensured the right to health, because they were related to measurement of organizational processes of the Agency. This distance can be analyzed from the viewpoint of the clash between the constitutional guarantee of rights and the submission to hegemonic political project in a particular historical context.

Keywords: Health Planning; Health Surveillance; Right to Health.

\section{Introdução}

No Estado moderno liberal, a noção de direito se refere sempre a um projeto de governabilidade e é carregada de ambiguidade, como destaca Castel, ${ }^{(1)}$ quando elucida que a palavra direito não tem o mesmo significado quando aplicada ao trabalho ou à assistência social. No primeiro caso, o Estado se recusa a assumir a responsabilidade sobre a subsistência por meio do trabalho, enquanto o direito à assistência é encarado como uma obrigação com a dívida social, quitada em diferentes graus de intervenção. Essa relação entre a concepção de direito e o contexto histórico-político fica evidente na tradicional descrição das gerações de direitos: a primeira inclui os direitos civis e políticos; a segunda inclui os direitos econômicos, sociais e culturais; e a terceira abrange os chamados direitos difusos. ${ }^{(2)}$

Os direitos civis e políticos foram assegurados em contraposição à arbitrariedade de poder no Estado absolutista do século XVIII e, por isso, representam o triunfo da burguesia, a sua ordem e o seu conceito de democracia, estando relacionados fundamentalmente à ideia de liberdade. A reivindicação por maior igualdade, inclusive para o exercício desses direitos, partiu dos movimentos sociais oriundos da classe social emergente durante o século XIX, o proletariado. Diferente dos direitos civis e políticos, os direitos de segunda geração exigem uma atuação estatal efetiva por parte do Estado para a sua materialização, sendo por isso também chamados de direitos positivos ou prestacionais. A terceira geração de direitos é considerada por alguns autores como uma expressão dos direitos sociais no contexto da globalização e dos avanços tecnológicos recentes. Não possuem titularidade clara e incluem pressupostos muito distintos. ${ }^{(3)}$

\footnotetext{
${ }^{1}$ CASTEL, Robert. As metamorfoses da questão social: uma crônica do salário. Petrópolis: Vozes, 2008.

2 MARSHALL, Thomas Humphrey. Cidadania, classe social e status. Rio de Janeiro: Zahar Editores, 1967.

${ }^{3}$ MARTINEZ DE PISÓN, José. Políticas de bienestar. un estúdio sobre los derechos sociales. Madrid: Tecnos, 1998.
} 
No caso dos direitos sociais, a prestação positiva por parte do Estado se materializa mediante políticas sociais, por meio de um conjunto de benefícios e serviços oferecidos à população, em resposta às suas necessidades sociais. Desde sua origem, com a Speenhamland Law, na Grã-Bretanha, em 1795, o conceito de proteção social tem variado bastante, estando sujeita tanto à necessidade de salvaguardar os fundamentos da ordem capitalista quanto à pressão dos movimentos organizados de trabalhadores. ${ }^{(4)}$ Mais recentemente, partir dos anos 1960, o avanço do capitalismo mundial conjugou, numa primeira etapa, a desregulamentação dos mercados financeiros e a redução do Estado e da despesa pública, o que afetou profundamente os programas sociais. Além disso, as mudanças nas relações produtivas, com ênfase na flexibilidade, levaram à precarização do trabalho e perda dos direitos. ${ }^{(5)}$

É essa a conjuntura de criação do Sistema Único de Saúde (SUS), por meio da Constituição Federal de 1988, concebido como de cunho universal, caráter descentralizado e natureza participativa. Concebido desde a década de 1970, por meio do movimento sanitário, foi descrito como "um movimento ideológico com uma prática política" e que teve as suas bases nos departamentos de medicina preventiva de diversas universidades. ${ }^{(6)}$ Ao lado disso, a intensa mobilização em fóruns de participação social, como as conferências nacionais de saúde, teve uma importância fundamental na criação e implementação do SUS e com repercussão em outras áreas governamentais que também realizaram conferências. ${ }^{(7)}$

Essa ampla participação dos movimentos sociais na formulação de ideias e debates que precederam a promulgação da Carta Magna garantiu que o texto constitucional conformasse o SUS como um sistema público, universal e democrático, um marco para as políticas sociais no país. A saúde está inserida no Capítulo II - Seguridade Social do Título VIII - Da Ordem Social. Com isso, fica estabelecida uma primeira inovação no desenho das políticas sociais brasileiras, a concepção da seguridade social, visando articular as políticas de saúde (SUS), de previdência social e de assistência social e integrar os recursos orçamentários. ${ }^{(8)}$

No primeiro artigo da seção sobre saúde na Constituição Federal, o artigo 196, a saúde é definida como "direito de todos e dever do Estado, garantido mediante políticas sociais e econômicas que visem à redução do risco de doença e de

\footnotetext{
${ }^{4}$ PEREIRA, Potyara Amazoneida P. Necessidades Humanas: subsídios à crítica dos mínimos sociais. São Paulo: Cortez, 2000.

5 IAMAMOTO, Marilda. Serviço Social em Tempo de Capital Fetiche. São Paulo: Cortez, 2007.

${ }^{6}$ ESCOREL, Sarah; NASCIMENTO, Dilene R.; EDLER, Flavio C. As origens da Reforma Sanitária e do SUS. In: LIMA, Nísia Trindade (Org.). Saúde e Democracia: história e perspectivas do SUS. Rio de Janeiro: Editora Fiocruz, 2005. p. 27-58.

7 ESCOREL, Sarah; BLOCH, Renata A. As Conferências Nacionais de Saúde na Construção do SUS. In: LIMA, Nísia Trindade (Org.). Saúde e Democracia: história e perspectivas do SUS. Rio de Janeiro: Editora Fiocruz, 2005. p. 59-82.

${ }^{8}$ CORDEIRO, Hésio. Descentralização, universalidade e eqüidade nas reformas da saúde. Ciência \& Saúde Coletiva, Rio de Janeiro, v. 6, n. 2, p. 319-328, 2001.
} 
outros agravos e ao acesso universal e igualitário às ações e serviços para sua promoção, proteção e recuperação". Nessa afirmação, está embutido o conceito ampliado de saúde, que aparece na Lei $n^{\circ} 8.080 / 90,{ }^{(9)}$ que enumera alguns dos fatores determinantes e condicionantes da saúde, como a alimentação, a moradia, o saneamento básico, o trabalho, a renda, a educação, o lazer e o acesso aos bens e serviços essenciais, concluindo que "os níveis de saúde da população expressam a organização social e econômica do País".

Mais de dez anos após a criação do SUS, e no contexto de redução do Estado e desregulamentação de suas obrigações, é criada a primeira agência reguladora na área social do país, a Agência Nacional de Vigilância Sanitária (Anvisa). Aconvergência de fatores sociais, políticos e econômicos, analisados por Piovesan, ${ }^{(10)}$ resultou na adoção do modelo de agência reguladora, com a criação da Anvisa. No contexto da reforma do Estado no Brasil, da globalização da economia e do aprofundamento da crise do capital, a estratégia adotada para a superação dos problemas do setor foi, portanto, uma agência reguladora com as prerrogativas de autonomia decisória e financeira, além de estabilidade dos seus dirigentes. Ao mesmo tempo, a década de 1990 apresentou imensos desafios à implementação do SUS, com o estabelecimento das reformas administrativas no Estado sem uma correspondente ampliação da cidadania e controle social sobre suas burocracias e aparelhos de poder. ${ }^{(11)}$ No que diz respeito às atividades de regulação sanitária, o quadro é de desequilíbrio entre as partes envolvidas - Estado, sociedade e setor produtivo, ${ }^{(12)}$ de forma que uma atuação frágil da vigilância sanitária pode impactar negativamente sobre o gerenciamento do risco sanitário e, portanto, sobre o quadro de saúde da população.

Se por um lado a gestão do SUS obteve avanços significativos na década de 1990, por outro, vários autores apontam as restrições financeiras desse período como um dos maiores obstáculos à implementação efetiva do Sistema. Ao lado disso, e também no caso da vigilância sanitária, ficaram evidentes as dificuldades relacionadas ao modelo das agências, cuja autonomia, considerada por vezes excessiva, revelou a tendência estrutural de se distanciarem dos órgãos e da

\footnotetext{
9 BRASIL. Lei $n^{\circ}$ 8.080, de 19 de setembro de 1990. Dispõe sobre as condições para a promoção, proteção e recuperação da saúde, a organização e o funcionamento dos serviços correspondentes e dá outras providências. Diário Oficial [da] República Federativa do Brasil, Poder Executivo, Brasília, DF, 20 set. 1990.

${ }^{10}$ PIOVESAN, Márcia F. A Construção Política da Agência Nacional de Vigilância Sanitária. Dissertação (Mestrado) - Fundação Oswaldo Cruz, Rio de Janeiro, 2002.

${ }^{11}$ CODATO, A. N. Uma história política da transição brasileira: da ditadura militar à democracia. Revista de Sociologia Política de Curitiba, Curitiba, n. 25, p. 83-106, 2005.

${ }^{12}$ MARQUES, Maria Cristina C.; IBAÑEZ, Nelson. Questões sobre política de vigilância sanitária no Brasil. In: MARQUES, Maria Cristina C. (Org.). Vigilância Sanitária: teoria e prática. São Carlos: E. Rima, 2006. p 1-32.
} 
política setorial aos quais estão vinculadas. ${ }^{(13),(14),(15)} \mathrm{O}$ distanciamento histórico das práticas de saúde, evidenciado pela escassez de indicadores que expressem a efetividade de suas ações, acabou por reforçar a noção de vigilância sanitária como prática centrada apenas no controle, sendo muitas vezes vista como alheia ao conceito de vigilância em saúde pública. ${ }^{(16)}$

Embora as ações de vigilância sanitária nas três esferas representem um espaço privilegiado de promoção e garantia do direito à saúde, ${ }^{(17)}$ também evidenciam problemas históricos ainda vigentes, que resultaram em baixa vinculação com o SUS. Se por um lado a capacidade de intervenção dessas ações sobre os indicadores de saúde é perceptível, por outro, nem sempre é possível quantificar o grau ou intensidade dessa intervenção. Assim é que a medida de atuação do Sistema Nacional de Vigilância Sanitária (SNVS), embora voltada para a melhoria das condições de saúde, não tem sido avaliada - e é, portanto, pouco conhecida - sob o ponto de vista dos indicadores epidemiológicos tradicionais, tais como mortalidade e morbidade. ${ }^{12}$ Este trabalho tem por objetivo investigar a forma de inserção da noção de direito à saúde nos compromissos estabelecidos pela vigilância sanitária no Plano Nacional de Saúde, um dos principais instrumentos de planejamento do SUS durante a década de 2000.

\section{O Plano Nacional de Saúde}

O processo de planejamento do SUS, definido na Lei ${ }^{\circ} 8.080 / 90$, é ascendente e acontece nas três esferas de gestão, federal, estadual e municipal. A base para as programações de atividades e recursos necessários em cada esfera são os planos de saúde. Além dos planos, outros instrumentos de planejamento são utilizados pelo sistema, visando imprimir uma lógica nacional de funcionamento e articular as diferentes esferas com relação às práticas e ações de saúde. ${ }^{(18)}$

O PNS constitui um dos três instrumentos básicos de planejamento do SUS, ao lado da Programação Anual de Saúde e do Relatório Anual de Gestão. O plano consolida, em cada esfera de governo, o processo de planejamento em

\footnotetext{
${ }^{13}$ COSTA, Ricardo Cesar R. Descentralização, financiamento e regulação: a reforma do sistema público de saúde no Brasil durante a década de 1990. Revista de Sociologia Política, São Paulo, n. 18, p. 49-71, 2002.

${ }^{14}$ NORONHA, José Carvalho; SOARES, Laura Tavares. A política de saúde no Brasil nos anos 90. Ciência \& Saúde Coletiva, São Paulo, v. 6, n. 2, p. 445-450, 2001.

${ }^{15}$ SILVA, Pedro Luiz Barros. Serviços de Saúde: o dilema do SUS na nova década. São Paulo em Perspectiva, São Paulo, v. 17, n. 1, p. 69-85, 2003.

${ }^{16}$ SILVA JÚNIOR, J. B. Epidemiologia em Serviço: uma avaliação de desempenho do Sistema Nacional de Vigilância em Saúde. 2004. Tese (Doutorado em Saúde Coletiva) - Faculdade de Ciências Médicas, Universidade Estadual de Campinas, Campinas, 2004.

${ }^{17}$ CAMPOS, Gastão Wagner de Sousa. Vigilância Sanitária: responsabilidade pública na proteção e promoção da saúde. p. 10. Disponível em <http://www.anvisa.gov.br/divulga/ conavisa/cadernos/ eixo1_texto01.pdf >. Acesso em: 12 out. 2008.

${ }^{18}$ BRASIL. Ministério da Saúde. Sistema Único de Saúde (SUS): instrumentos de gestão em saúde. Brasília: Ministério da Saúde, 2002. p. 46.
} 
saúde para um período de quatro anos, de forma articulada e integrada ao Plano Plurianual (PPA). Apesar da definição legal sobre esses instrumentos, o primeiro PNS pós-Constituição só foi publicado em 2004. O relatório da $11^{a}$ Conferência Nacional de Saúde, ${ }^{(19)}$ quando aborda a gestão do SUS, aponta que a falta dos planos nacional, estaduais e municipais de Saúde expressava, naquele momento, a ausência de rumo claro para a política de saúde. Isso resultava, no nível local, na definição dos modelos de atenção locais a partir dos mecanismos de financiamento.

A Portaria do Ministério da Saúde $n^{\circ} 548 / 01^{(20)}$ aprovou as orientações federais para a elaboração e aplicação do Plano de Saúde e de outros instrumentos de gestão do SUS. Com relação ao plano de saúde, foram definidos aspectos como: (i) os planos devem corresponder, em relação ao seu período, ao horizonte de tempo da gestão em cada esfera; (ii) os planos são documentos de intenções políticas, de diagnóstico, de estratégias, de prioridades e de metas, que devem ser submetidos na íntegra aos respectivos conselhos de saúde; (iii) a formulação e o encaminhamento do Plano Nacional de Saúde são competência exclusiva do Ministério da Saúde, cabendo ao Conselho Nacional de Saúde (CNS) apreciá-lo e propor as modificações necessárias.

Mais tarde, em 2006, as Portarias do Ministério da Saúde de $n^{\circ} 3.085^{(21)}$ e $\mathrm{n}^{\circ} 3.332^{(22)}$ regulamentaram o Sistema de Planejamento do SUS e definiram o conceito e orientações gerais sobre o Plano de Saúde. ${ }^{(23)}$ Segundo essas normativas, o plano deve refletir as necessidades e peculiaridades próprias de cada esfera, compondo a base para a execução, o acompanhamento, a avaliação e a gestão do sistema de saúde. Deve, ainda, contemplar todas as áreas da atenção à saúde, em consonância com o princípio da integralidade, e a sua formulação compreende dois momentos: o da análise situacional e o da definição dos objetivos, diretrizes e metas para o período de quatro anos.

\footnotetext{
${ }^{19}$ BRASIL. Ministério da Saúde. Relatório Final da $11^{a}$ Conferência Nacional de Saúde. Efetivando o SUS: acesso, qualidade e humanização da atenção à saúde com controle social. Brasília: Ministério da Saúde, 2001. p. 198.

${ }^{20}$ BRASIL. Ministério da Saúde. Portaria n 548, de 12 de abril de 2001. "Aprova o documento de Orientações Gerais para a Elaboração e Aplicação da Agenda de Saúde, do Plano de Saúde, dos Quadros de Metas, e do Relatório de Gestão como Instrumentos de Gestão do SUS, parte integrante desta portaria.". Disponível em: <http://dtr2004.saude.gov.br/susdeaz/legislacao/ arquivo/35_Portaria_548_de_12_04_2001.pdf>. Acesso em: 19 jan. 2014.

${ }^{21}$ BRASIL. Ministério da Saúde. Portaria $\mathrm{n}^{\circ} 3.085$, de $1^{\circ}$ de dezembro de 2006. "Regulamenta o Sistema de Planejamento do SUS.”. Disponível em: < http://dtr2001.saude.gov.br/sas/PORTARIAS/ Port2006/GM/GM-3085.htm>. Acesso em: 19 jan. 2014.

${ }^{22}$ BRASIL. Ministério da Saúde. Portaria $n^{\circ} 3.322$, de 27 de dezembro de 2006. "Estabelece recursos a serem incorporados ao limite financeiro anual da Assistência Ambulatorial e Hospitalar de Média e Alta Complexidade do Estado de Minas Gerais e do Município de Uberlândia (MG).”. Disponível em: < http://dtr2001.saude.gov.br/sas/PORTARIAS/Port2006/GM/GM-3322.htm>. Acesso em: 19 jan. 2014.

${ }^{23}$ BRASIL. Ministério da Saúde. Sistema de Planejamento do SUS (PlanejaSUS): uma construção coletiva - trajetória e orientações de operacionalização. Brasília: Ministério da Saúde, 2009. p. 318.
} 
Segundo definição do Ministério da Saúde, ${ }^{(24)}$ o plano "é, enfim, o instrumento que norteia todas as medidas empreendidas pelo SUS no respectivo âmbito e que explicita a Política Nacional de Saúde - expressa na Constituição Federal e nas Leis Orgânicas da Saúde - e as políticas específicas".

Dois Planos Nacionais de Saúde foram publicados depois da Constituição Federal, no período entre 2004 e 2011: um para o período de 2004 a $2007^{(25)}$ e outro, em vigência, de 2008 a 2011. ${ }^{(26)}$ A construção do primeiro teve início em meados de 2003, após a conclusão do Plano Plurianual/PPA 2004-2007 do setor saúde, e envolveu formulações técnicas do próprio Ministério, contribuições dos participantes da $12^{a}$ Conferência Nacional de Saúde e o conteúdo do PPA 2004-2007. O Plano passou por etapas de validação junto aos dirigentes do Ministério da Saúde, colegiados de gestores do SUS, até a sua aprovação final pelo Conselho Nacional de Saúde.

A elaboração do Plano Nacional de Saúde/PNS 2008-2011 teve início em fevereiro de 2007, em processo integrado à formulação do PPA. Vários documentos subsidiaram essa formulação, entre eles: os compromissos assumidos pelo Ministério da Saúde em outros instrumentos de gestão, o Relatório Final da $13^{a}$ Conferência de Saúde, as avaliações do PPA e do próprio PNS anterior, os planos estaduais e municipais de saúde e os Objetivos do Milênio para 2015. O PNS 2008-2011 está estruturado em três partes: (i) análise situacional; (ii) objetivos, diretrizes e metas para o período; e (iii) operacionalização, monitoramento e avaliação do PNS.

\section{Procedimentos metodológicos}

Para analisar a participação da Anvisa, as seguintes etapas de estudo foram desenvolvidas neste trabalho:

1. identificação dos compromissos sob a responsabilidade direta e indireta da Agência nos PNS 2004-2007 e 2008-2011;

2. análise comparativa dos compromissos nos dois períodos, sob o ponto de vista quantitativo (número) e qualitativo (conteúdo);

3. os eixos de intervenção adotados para o estudo correspondem aos três eixos adotados para a análise situacional e para a formulação de objetivos, diretrizes e metas nos dois planos. ${ }^{(27),(28)}$

\footnotetext{
${ }^{24}$ BRASIL. Ministério da Saúde. Sistema de Planejamento do SUS (PlanejaSUS): uma construção coletiva - trajetória e orientações de operacionalização. Brasília: Ministério da Saúde, 2009. p. 30.

${ }^{25}$ BRASIL. Ministério da Saúde. Plano Nacional de Saúde: um pacto pela saúde no Brasil - síntese. Brasília: Ministério da Saúde, 2005. p. 24.

${ }^{26}$ BRASIL. Ministério da Saúde. Sistema de Planejamento do SUS: uma construção coletiva - Plano Nacional de Saúde (PNS) 2008/2009-2011. Brasília: Ministério da Saúde, 2010. p. 166.

${ }^{27}$ BRASIL. Ministério da Saúde. Sistema de Planejamento do SUS (PlanejaSUS): uma construção coletiva - trajetória e orientações de operacionalização. Brasília: Ministério da Saúde, 2009, cit.

${ }^{28}$ BRASIL. Ministério da Saúde. Plano Nacional de Saúde: um pacto pela saúde no Brasil - síntese. Brasília: Ministério da Saúde, 2005, cit.
} 
Foram considerados como compromissos sob a responsabilidade direta da Agência aqueles cuja execução depende de sua ação e cujos resultados estão sob a sua governabilidade, ainda que considerando as limitações inerentes a cada um deles. Os compromissos sob responsabilidade indireta da Agência são aqueles que, embora a execução e resultados estejam sob controle de outro órgão, dependem das ações desempenhadas pela Agência para o alcance dos objetivos propostos e diretrizes estabelecidas, havendo menção explícita no texto a essa atuação.

\section{A participação da Anvisa nos Planos Nacionais de Saúde}

\section{Compromissos sob a responsabilidade direta da Anvisa}

Os compromissos sob responsabilidade direta da Agência são descritos a seguir, com relação aos objetivos, diretrizes e metas pactuadas, segundo os recortes do PNS 2004-2007, que são: (i) linhas de atenção à saúde; (ii) condições de saúde da população; (iii) setor saúde; (iv) gestão em saúde; e (v) investimento em saúde.

O PNS 2008-2011 apresenta quatro objetivos e 12 diretrizes agrupadas sob três recortes: (i) condições de saúde da população; (ii) determinantes e condicionantes de saúde; e (iii) gestão em saúde. O Quadro 4 apresenta as três metas sob responsabilidade direta no documento.

Quadro 1. Compromissos sob a responsabilidade direta da Anvisa no Plano Nacional de Saúde 2004-2007, em relação às linhas de atenção à saúde.

Objetivo: promover o acesso à assistência farmacêutica e aos insumos estratégicos, nos diversos níveis da atenção à saúde, observando as especificidades e as prioridades regionais definidas nas instâncias gestoras do SUS e adotando medidas que favoreçam a redução dos custos e dos preços.

Diretriz: ampliação das ações de regulação de mercado.

Renovar 3/5 dos registros de medicamentos similares das classes terapêuticas antibióticos, antineoplásicos e antirretrovirais - com base na comprovação de testes de biodisponibilidade relativa.

Renovar 3/5 dos registros de medicamentos similares em comercialização no mercado brasileiro, com base na comprovação de testes de equivalência farmacêutica.

Proceder à análise fiscal de cerca de $17 \%$ das especialidades de medicamentos disponíveis para o consumo.

Implantar sistema de bula eletrônica, com consulta de informações, via Internet, de 11 mil apresentações de medicamentos comercializados. 
Quadro 2. Compromissos sob a responsabilidade direta da Anvisa no Plano Nacional de Saúde 2004-2007, em relação às condições de saúde da população.

Objetivo: promover a atenção à saúde de grupos populacionais mais vulneráveis - em especial os povos indígenas -, de portadores de patologias e deficiências, mediante a adoção de medidas que contribuam para a sua qualidade de vida.

Diretriz: promoção da saúde da população indígena segundo as suas especificidades.

Implementar ações de vigilância sanitária em 100\% dos Distritos Sanitários Especiais Indígenas.

Diretriz: implementação da atenção à saúde da população prisional.

Instrumentar e capacitar o Sistema Nacional de Vigilância Sanitária nos 27 estados e no DF para ações de controle de riscos sanitários no Sistema Penitenciário.

Diretriz: promoção da alimentação saudável e combate à desnutrição.

Monitorar a fortificação das farinhas de trigo e milho nas 27 unidades federadas.

Quadro 3. Compromissos sob a responsabilidade direta da Anvisa no Plano Nacional de Saúde 2004-2007, em relação ao setor saúde.

Objetivo: garantir a devida segurança, eficácia e qualidade dos produtos, insumos, serviços e ambientes de interesse para a saúde pública, bem como combater adulterações de produtos, concorrências desleais e disfunções técnicas, visando à proteção da saúde da população.

Diretriz: vigilância sanitária de produtos, serviços e ambientes.

Realizar cerca de 27 mil inspeções/ano relativas a produtos sujeitos ao regime de vigilância sanitária (medicamentos e produtos para a saúde, alimentos, cosméticos e saneantes domissanitários).

Realizar a análise técnico-laboratorial da qualidade de cerca de 5,4 mil produtos/ano ofertados para o consumo da população.

Realizar inspeção sanitária anual em cerca de 7 mil serviços de saúde.

Realizar cerca de 3,3 milhões de fiscalizações no âmbito da vigilância sanitária em portos, aeroportos, fronteiras e recintos alfandegados.

Implementar as câmaras setoriais da Agência Nacional de Vigilância Sanitária, previstas em seu regulamento.

Objetivo: fomentar ações de saneamento ambiental voltadas à prevenção e ao controle de doenças.

Diretriz: destinação adequada dos resíduos sólidos urbanos.

Garantir 100\% de fiscalização do Programa de Gerenciamento de Resíduos de Serviços de Saúde nos estabelecimentos a serem inspecionados, objeto do Termo de Ajustes e Metas (TAM).

Capacitar $100 \%$ das áreas de vigilância sanitária estaduais para as ações de inspeção na área de resíduos de serviços de saúde 
Quadro 4. Compromissos sob a responsabilidade direta da Anvisa no Plano Nacional de Saúde 2008-2011, em relação às condições de saúde da população.

Objetivo: prevenir e controlar doenças, outros agravos e riscos à saúde da população.

Diretriz: prevenção e controle de riscos à saúde decorrentes da produção e do consumo de bens e serviços.

Ampliar o número de certificações de boas práticas de fabricação (BPF) concedidas a empresas de medicamentos e insumos farmacêuticos, passando de 407 BPF em 2007 para 709 até 2011.

Ampliar em $44 \%$ o número de notificações de eventos adversos de medicamentos no Notivisa (Sistema de Notificações em Vigilância Sanitária), passando de 2.060 em 2007 para 2.966 em 2011.

Ampliar o número de municípios com ações estratégicas de vigilância sanitária pactuadas na CIB, passando de 1.637 em 2007 para 4.448 até 2011.

\section{Compromissos sob a responsabilidade indireta da Anvisa}

Os compromissos sob responsabilidade indireta da Agência no PNS 2004-2007 estão incluídos em dois recortes: condições de saúde da população (Quadro 5) e setor saúde (Quadro 6).

No PNS 2008-2011, os compromissos sob responsabilidade indireta da Agência pertencem aos recortes de condições de vida da população (Quadro 7) e determinantes e condicionantes da saúde (Quadro 8).

\section{Análise dos resultados}

Segundo Dallari, ${ }^{(29)}$ a efetivação do direito à saúde envolve, por um lado, a responsabilidade da esfera municipal nessas ações e, por outro, a necessidade de um sistema de planejamento nacional que oriente o estabelecimento de objetivos, ações e recursos por parte das esferas estadual e municipal. No SUS, a função de planejamento é uma atribuição comum das três esferas de governo, em suas respectivas esferas de atuação. Paim ${ }^{(30)}$ destaca a potencialidade do planejamento em contribuir para o exercício da cidadania, desde que superado o seu caráter normativo. Dessa forma, segundo o autor, o planejamento vai além da produção de planos, programas ou projetos - é a sensibilização e comprometimento dos reais interessados na mudança da situação que permite modificar a realidade.

\footnotetext{
${ }^{29}$ DALLARI, Sueli Gandolfi. O direito à saúde. Revista de Saúde Pública, São Paulo, v. 22, n. 1, p. 57-63, 1988.

${ }^{30}$ PAIM, Jairnilson Silva. Comentário: O "Plano Nacional de Saúde" de 1967 e os "planos de saúde", hoje: algo em comum?, Revista de Saúde Pública, São Paulo, v. 40, n. 3, p. 386-8, 2006.
} 
Quadro 5. Compromissos sob a responsabilidade indireta da Anvisa no Plano Nacional de Saúde 2004-2007, em relação às condições de saúde da população.

Objetivo: promover a atenção à saúde de grupos populacionais mais vulneráveis - em especial os povos indígenas -, de portadores de patologias e deficiências, mediante a adoção de medidas que contribuam para sua qualidade de vida.

Diretriz: adoção de linhas de cuidado na atenção integral à saúde da criança. Participação da vigilância sanitária: Todas as ações dessas linhas prioritárias reforçarão processos inerentes a duas grandes metas de impacto: a redução da mortalidade infantil e da mortalidade neonatal, em especial, tendo como pressuposto básico a diminuição das desigualdades sociais e de raça existentes e que são evidenciadas pelos coeficientes diferenciados entre crianças pobres e ricas, negras e brancas. Para tanto, será promovida também a regulamentação de normas relativas à vigilância sanitária que orientem ações para a redução da mortalidade materno-infantil.

Diretriz: promoção da saúde do trabalhador com melhoria das condições de vida e da atenção à saúde.

Participação da vigilância sanitária: No conjunto das medidas voltadas à saúde do trabalhador, especial ênfase será dada à prevenção de riscos e à promoção da qualidade de vida no trabalho, entre as quais se destacam a vigilância sanitária e ambiental dos processos de trabalho, assim como a vi+gilância epidemiológica dos agravos relacionados ao trabalho.

Diretriz: ampliação da atenção em saúde mental.

Participação da vigilância sanitária: Os profissionais em vigilância sanitária serão capacitados para o monitoramento de eventos sentinela dos riscos próprios à internação em hospitais psiquiátricos. Buscar-se-á também capacitar o Sistema Nacional de Vigilância Sanitária para o controle sanitário em hospitais psiquiátricos, manicômios judiciários e comunidades terapêuticas. O controle sanitário nessas instituições estimulará ações preventivas em relação aos agravos decorrentes das estruturas e de processos de trabalho existentes. Ao lado disso, deverá ser promovida a regulamentação da publicidade e da comercialização de bebidas alcoólicas.

Para Noronha et al, ${ }^{(31)}$ a existência de um Plano Nacional de Saúde formal é um mecanismo para explicitar prioridades e minimizar as intensas variações quanto ao conteúdo dos planos e abrangência das ações, decorrentes da heterogeneidade dos estados e municípios no país. Entretanto, outras limitações, de natureza diversa, podem impactar negativamente sobre a capacidade transformadora desses instrumentos, tais como a baixa coordenação nacional das ações, a insuficiente regulamentação do financiamento no setor saúde e os problemas estruturais do sistema de saúde. ${ }^{(32),(33)}$

\footnotetext{
${ }^{31}$ NORONHA, José Carvalho; LIMA, Luciana Dias; MACHADO, Cristiani Vieira. A gestão do Sistema Único de Saúde: características e tendências. In: BRASIL. Ministério da Saúde. Saúde no Brasil contribuições para a Agenda de Prioridades de Pesquisa. Brasília: Ministério da Saúde, 2004.

${ }^{32}$ DALLARI, Sueli Gandolfi. op. cit.

${ }^{33}$ MACHADO, Cristiani Vieira; BAPTISTA, Tatiana Wargas de Faria; LIMA, Luciana Dias. O planejamento nacional da política de saúde no Brasil: estratégias e instrumentos nos anos 2000. Ciência \& Saúde Coletiva, São Paulo, v. 15, n. 5, p. 2367-2382, 2010.
} 
Quadro 6. Compromissos sob a responsabilidade indireta da Anvisa no Plano Nacional de Saúde 2004-2007, em relação ao setor saúde.

Objetivo: formular e implementar a política nacional de ciência, tecnologia e inovação em saúde, orientada por padrões éticos, buscando a equidade e a regionalização, com valorização de tecnologias nacionais.

Diretriz: construção da agenda nacional de prioridades de pesquisa em saúde.

Participação da vigilância sanitária: Meta: realizar cinco pesquisas anuais em áreas de conhecimento do interesse da vigilância sanitária, mediante estabelecimento de parcerias de cooperação técnica com centros de pesquisa e universidades brasileiras e estrangeiras, e contratação de pesquisadores e consultores.

A análise da participação da Anvisa no PNS, nos períodos de 2004 a 2007 e 2008 a 2011, revela algumas diferenças nos dois momentos, sendo que a primeira evidência é quantitativa. No PNS 2004-2007, que tinha 171 metas estabelecidas, a Anvisa assumiu 14 compromissos ( $8,2 \%$ do total) de sua responsabilidade direta, enquanto no PNS seguinte (com 71 metas, no total) foram assumidos três compromissos (4,2\%) do tipo. Ainda, no PNS 2004-2007, a participação indireta da Anvisa nos demais compromissos estava mencionada em quatro diretrizes, enquanto no Plano 2008-2011 isso aconteceu em duas diretrizes. Entretanto, além da dimensão quantitativa, algumas características das metas pactuadas diferenciam a inserção da Agência nos dois períodos.

A abrangência das ações a que se referem as metas pactuadas é maior no primeiro período, ou seja, os compromissos se referem a um número maior de objetos, inclusive de natureza intersetorial, como no caso da atenção à saúde da população prisional e saneamento básico. Em relação ao conteúdo dos compromissos, há implicações na garantia do direito à saúde, tal como definido constitucionalmente. Enquanto no PNS 2004-2007 12 dos 14 compromissos diretos da Agência estão relacionados à redução do risco de doença e ao acesso às ações e serviços de saúde, no PNS 2008-2011 nenhum dos três compromissos assegura a garantia do direito à saúde, por se tratar de mensuração de processos organizacionais da Agência.

A certificação de boas práticas de fabricação a empresas de medicamentos e insumos corresponde ao preenchimento de uma série de requisitos para esse ciclo produtivo e se relaciona, portanto, à segurança do produto. Nesse sentido, Rangel-S et $\mathrm{a}^{\left({ }^{34)}\right.}$ atentam para o fato de que as bases constitucionais do SUS apontam para a "indissociabilidade entre as condições de saúde dos indivíduos e das populações e a forma de organização da sociedade". Assim é que a vigilância sanitária, por atuar no espaço conflituoso das relações capitalistas

\footnotetext{
${ }^{34}$ RANGEL-S, Maria Ligia; MARQUES, Tetê; COSTA, Ediná Alves. Risco, vigilância sanitária e comunicação: subsídios para uma política de proteção e promoção da saúde. In: RANGEL-S, Maria Ligia; COSTA, Ediná Alves. Comunicação em Vigilância Sanitária: princípios e diretrizes para uma política. Salvador: EDUFBA, 2007. p. 13-39. p. 21
} 
Quadro 7. Compromissos sob a responsabilidade indireta da Anvisa no Plano Nacional de Saúde 2008-2011, em relação às condições de saúde da população.

Objetivo: ampliar o acesso da população aos serviços e promover a qualidade, a integralidade, a equidade e a humanização na atenção à saúde.

Diretriz: implementação da assistência farmacêutica e suprimento de outros insumos estratégicos.

Participação da vigilância sanitária: Para contribuir com o acesso da população a medicamentos seguros, a vigilância sanitária monitora os valores no mercado e analisa os preços dos produtos antes do seu lançamento, verificando se são inovadores ou se mantêm as características daqueles já disponíveis ao consumidor. Somado a isso, implementa uma série de medidas para estimular a concorrência e possibilitar a redução de preços, como ocorre com os genéricos, cujos custos devem ser pelo menos $35 \%$ mais baixos do que os medicamentos de referência.

Em 2007, a Anvisa concedeu 610 novos registros para medicamentos com 2.745 apresentações diferentes (a maior parte relativa a medicamentos genéricos). Ao final daquele ano, constavam no banco de dados da instituição 8.584 medicamentos, em 42.659 apresentações diferentes, com registros válidos no País. No mesmo ano, foram liberadas as versões genéricas de quatro anticoncepcionais de referência, que estão entre os 20 mais vendidos no País, setor esse que teve faturamento superior a $R \$ 1,5$ bilhão em 2006 - cerca de $12 \%$ do faturamento da indústria farmacêutica no Brasil - e representa $14 \%$ do total de medicamentos comercializados. Há, atualmente, 2.260 genéricos registrados, fabricados por 73 laboratórios. No tocante às autorizações de funcionamento de empresas (AFE) para estabelecimentos da cadeia farmacêutica, foram emitidas, em 2007, 62 para fabricantes de insumos com ingredientes ativos, 311 para fabricantes de medicamentos e 1.053 para distribuidores, importadores e exportadores, totalizando 1.426 AFE emitidas.

de produção e consumo, deve se afastar do valor simbólico da mercadoria, que mascara práticas de risco à saúde, detendo-se ao atendimento das necessidades humanas. O segundo compromisso, de aumento do número de notificações de eventos adversos por medicamentos, pretende medir o incremento da captação dessas informações, mas não apresenta resultados quanto à melhoria da saúde da população no que tange às intoxicações medicamentosas, tendo em vista que os medicamentos são os agentes das principais intoxicações no país. ${ }^{\left({ }^{35}\right)}$ Por fim, a medida da pactuação de ações estratégicas pelos municípios se refere ao processo de descentralização tardia pela vigilância sanitária ${ }^{(36)}$ que, embora represente um avanço no processo de municipalização dessas ações, não reflete melhorias no arranjo sistêmico e execução das atividades necessárias para a regulação e controle sanitário.

\footnotetext{
${ }^{35}$ MENDONÇA, Reginaldo; MARINHO, Jaqueline. Discussão sobre intoxicações por medicamentos e agrotóxicos no Brasil de 1999 a 2002. Revista Eletrônica de Farmácia, Goiânia, v. 2, n. 2, p. 45-63, 2005. ${ }^{36}$ BRITO, Rodrigo Lino. Análise da política de descentralização das ações de vigilância sanitária no Brasil: do debate sobre o repasse de recursos ao compromisso com a responsabilidade sanitária. 2007. Dissertação (Mestrado) -Fundação Oswaldo Cruz, Recife, 2007.
} 
Quadro 8. Compromissos sob a responsabilidade indireta da Anvisa no Plano Nacional de Saúde 2008-2011, em relação aos determinantes e condicionantes da saúde.

Objetivo: promover e participar da adoção de medidas voltadas à prevenção e ao controle de determinantes e condicionantes da saúde da população.

Diretriz: implementação da ciência, tecnologia e inovação no complexo da saúde.

Participação da vigilância sanitária: Nesse contexto ainda, constituirão foco de atenção: (i) o investimento nos produtores públicos de vacinas, visando ao atendimento das necessidades do PNI e dotando o Brasil de capacitação tecnológica e competitiva em novos imunobiológicos; (ii) o investimento em produtores públicos de medicamentos; (iii) o fomento à capacidade produtiva e de inovação nas indústrias privadas nacionais de medicamentos, equipamentos e materiais, em parceria com o BNDES e a Finep; (iv) a regulamentação e adequação da legislação de compras, para permitir o uso estratégico do poder de aquisição do Estado para produtos inovadores de alta essencialidade para a saúde, bem como o aperfeiçoamento da política tributária e tarifária para garantir a competitividade da produção local; (v) a implantação do centro de desenvolvimento tecnológico em saúde na Fiocruz, provendo o País de uma plataforma de serviços tecnológicos em saúde, capaz de atender à demanda das instituições científicas e tecnológicas e das empresas; (vi) a promoção e modernização do Sistema Nacional de Vigilância Sanitária para garantir a qualidade e a eficiência do processo de produção e de inovação nacional, assegurando a harmonização regulatória em relação às importações, consoante à garantia da qualidade e da segurança dos produtos em saúde.

Portanto, segundo os dados analisados, a participação da Anvisa nos dois Planos Nacionais de Saúde durante os anos 2000 apontam para o distanciamento, a partir do Plano 2008-2011, do direito à saúde tal como estabelecido no SUS. Marques e Ibañez ${ }^{(37)}$ chamam a atenção para uma das armadilhas enfrentadas pela vigilância sanitária: a responsabilidade no gerenciamento do risco sanitário e atuação no campo de direito social, em confronto a um projeto político de redução do papel do Estado, inclusive enquanto provedor do direito à saúde. Assim, os compromissos assumidos pela Agência perante a Política Nacional de Saúde são, a um só tempo, expressão e indução de práticas e ações resultantes desse embate entre garantia constitucional de direitos e submissão ao projeto político hegemônico em determinado contexto histórico. A gestão das ações de vigilância sanitária, portanto, deve assimilar os princípios que norteiam a política de saúde no país, para então superar o caráter restrito da vigilância sanitária, centrado na segurança das mercadorias e serviços, e não na garantia do direito à saúde.

\footnotetext{
${ }^{37}$ MARQUES, Maria Cristina C.; IBAÑEZ, Nelson. op.cit.
} 


\section{Referências}

BRASIL. Lei $n^{\circ} 8.080$, de 19 de setembro de 1990. Dispõe sobre as condições para a promoção, proteção e recuperação da saúde, a organização e o funcionamento dos serviços correspondentes e dá outras providências. Diário Oficial [da] República Federativa do Brasil, Poder Executivo, Brasília, DF, 20 set. 1990.

Ministério da Saúde. Plano Nacional de Saúde: um pacto pela saúde no Brasil - síntese. Brasília: Ministério da Saúde, 2005.

Ministério da Saúde. Relatório Final da $11^{a}$ Conferência Nacional de Saúde. Efetivando o SUS: acesso, qualidade e humanização da atenção à saúde com controle social. Brasília: Ministério da Saúde, 2001.

. Ministério da Saúde. Sistema de Planejamento do SUS (PlanejaSUS): uma construção coletiva - trajetória e orientações de operacionalização. Brasília: Ministério da Saúde, 2009.

. Ministério da Saúde. Sistema de Planejamento do SUS: uma construção coletiva - Plano Nacional de Saúde (PNS) 2008/2009-2011. Brasília: Ministério da Saúde, 2010.

Ministério da Saúde. Sistema Único de Saúde (SUS): instrumentos de gestão em saúde. Brasília: Ministério da Saúde, 2002.

BRITO, Rodrigo Lino. Análise da política de descentralização das ações de vigilância sanitária no Brasil: do debate sobre o repasse de recursos ao compromisso com a responsabilidade sanitária. 2007. Dissertação (Mestrado) - Fundação Oswaldo Cruz, Recife, 2007.

CAMPOS, Gastão Wagner de Sousa. Vigilância Sanitária: responsabilidade pública na proteção e promoção da saúde. Disponível em <http://www.anvisa. gov.br/divulga/conavisa/cadernos/eixo1_texto01.pdf>. Acesso em: 12 out. 2008.

CASTEL, Robert. As metamorfoses da questão social: uma crônica do salário. Petrópolis: Vozes, 2008.

CODATO, A. N. Uma história política da transição brasileira: da ditadura militar à democracia. Revista de Sociologia Política de Curitiba, Curitiba, n. 25, p. 83106, 2005.

CORDEIRO, Hésio. Descentralização, universalidade e eqüidade nas reformas da saúde. Ciência \& Saúde Coletiva, Rio de Janeiro, v. 6, n. 2, p. 319-328, 2001.

COSTA, Ricardo Cesar R. Descentralização, financiamento e regulação: a reforma do sistema público de saúde no Brasil durante a década de 1990 . Revista de Sociologia Política, São Paulo, n. 18, p. 49-71, 2002. 
DALLARI, Sueli Gandolfi. O direito à saúde. Revista de Saúde Pública, São Paulo, v. 22, n. 1, p. 57-63, 1988.

ESCOREL, Sarah; BLOCH, Renata A. As Conferências Nacionais de Saúde na construção do SUS. In: LIMA, Nísia Trindade (Org.). Saúde e democracia: história e perspectivas do SUS. Rio de Janeiro: Ed. Fiocruz, 2005. p. 59-82.

; NASCIMENTO, Dilene R.; EDLER, Flavio C. As origens da Reforma Sanitária e do SUS. In: LIMA, Nísia Trindade (Org.). Saúde e Democracia: história e perspectivas do SUS. Rio de Janeiro: Editora Fiocruz, 2005. p. 27-58.

IAMAMOTO, Marilda. Serviço social em tempo de capital fetiche. São Paulo: Cortez, 2007.

MACHADO, Cristiani Vieira; BAPTISTA, Tatiana Wargas de Faria; LIMA, Luciana Dias. O planejamento nacional da política de saúde no Brasil: estratégias e instrumentos nos anos 2000. Ciência \& Saúde Coletiva, São Paulo, v. 15, n. 5, p. 2367-2382, 2010.

MARQUES, Maria Cristina C.; IBAÑEZ, Nelson. Questões sobre política de vigilância sanitária no Brasil. In: MARQUES, Maria Cristina C. (Org.). Vigilância Sanitária: teoria e prática. São Carlos: E. Rima, 2006. p 1-32.

MARSHALL, Thomas Humphrey. Cidadania, classe social e status. Rio de Janeiro: Zahar, 1967.

MARTINEZ DE PISÓN, José. Políticas de bienestar: un estúdio sobre los derechos sociales. Madrid: Tecnos, 1998.

MENDONÇA, Reginaldo; MARINHO, Jaqueline. Discussão sobre intoxicações por medicamentos e agrotóxicos no Brasil de 1999 a 2002. Revista Eletrônica de Farmácia, Goiânia, v. 2, n. 2, p. 45-63, 2005.

NORONHA, José Carvalho; LIMA, Luciana Dias; MACHADO, Cristiani Vieira. A Gestão do Sistema Único de Saúde: características e tendências. In: BRASIL. Ministério da Saúde. Saúde no Brasil - contribuições para a Agenda de Prioridades de Pesquisa. Brasília: Ministério da Saúde, 2004.

; SOARES, Laura Tavares. A política de saúde no Brasil nos anos 90. Ciência \& Saúde Coletiva, São Paulo, v. 6, n. 2, p. 445-450, 2001.

PAIM, Jairnilson Silva. Comentário: O "Plano Nacional de Saúde" de 1967 e os "planos de saúde", hoje: algo em comum? Revista de Saúde Pública, São Paulo, v. 40, n. 3, p. 386-388, 2006.

PEREIRA, Potyara Amazoneida P. Necessidades humanas: subsídios à crítica dos mínimos sociais. São Paulo: Cortez, 2000..

PIOVESAN, Márcia F. A construção política da Agência Nacional de Vigilância Sanitária. 2002. Dissertação (Mestrado) - Fundação Oswaldo Cruz, Rio de Janeiro, 2002. 
RANGEL-S, Maria Ligia; MARQUES, Tetê; COSTA, Ediná Alves. Risco, vigilância sanitária e comunicação: subsídios para uma política de proteção e promoção da saúde. In: RANGEL-S, Maria Ligia; COSTA, Ediná Alves. Comunicação em vigilância sanitária: princípios e diretrizes para uma política. Salvador: EDUFBA, 2007. p. 13-39.

SILVA, Pedro Luiz Barros. Serviços de saúde: o dilema do SUS na nova década. São Paulo em Perspectiva, São Paulo, v. 17, n. 1, p. 69-85, 2003.

SILVA JÚNIOR, J. B. Epidemiologia em serviço: uma avaliação de desempenho do Sistema Nacional de Vigilância em Saúde. 2004. Tese (Doutorado em Saúde Coletiva) - Faculdade de Ciências Médicas, Universidade Estadual de Campinas, Campinas, 2004. 